\title{
Coltan mining and internet privacy
}

\author{
Fahad Atif, Shawn Khan, and Adriel Gobin
}

\section{Abstract}

This research-informed action project focuses on coltan mining and online privacy. In particular, the atrocities being carried out in foreign countries in pursuit of coltan and the risks of privacy invasion one faces when browsing the internet. Although at first it may appear that coltan mining and internet privacy are entirely separate issues, we recognize that these issues are part of larger network, and thus, they are related to each other via many intermediate actants. Through surveys taken at Erindale Secondary
School, we learned that most people are significantly uninformed in regards to both topics. In response to these appalling results, the research team created three YouTube ${ }^{\mathrm{TM}}$ videos about coltan mining and internet privacy which included numerous facts about the issues and the actions that one can take. Additionally, a Facebook ${ }^{\mathrm{TM}}$ page was created to draw attention to the issues. The Facebook ${ }^{\mathrm{TM}}$ page has over 100 likes and the YouTube ${ }^{\mathrm{TM}}$ channel has over 1400 views. 


\section{Introduction}

Citizens of North American society and in many other societies around the world have access to vast amounts of information at their disposal in a matter of seconds. In an ideal world, this fruitful availability of knowledge would keep the average person informed about vital issues occurring around the world and on the net. Regrettably, this is not the case as many people are unaware of the current controversies regarding coltan mining and online privacy. Coltan is a dull metallic ore mined in numerous countries including Canada and Australia. The most notorious location of coltan mining is in the Democratic Republic of Congo. In the Democratic Republic of Congo, illegal and unregulated coltan mining has fuelled both sides of the civil war, forced people of all ages to undergo slave labour, dislocated local human populations, polluted water supplies, destroyed wildlife habitats, and aided surrounding countries in gaining revenue from smuggling coltan ("Coltan, gorillas and cellphones,"n.d.). Coltan is extremely sought after as when refined, tantalum is produced. Tantalum is heat resistant; it holds a high electrical charge; and thus, tantalum is great for manufacturing capacitors which store electrical charges in circuits that are used in many electronic devices such as phones, computers, game consoles, etc.

Powerful actors in this issue are multi-national corporations such as Bayer who have been known to purchase illegal coltan and environmental activists who fight against the destruction caused by unregulated and illegal coltan mining. Another matter requiring attention is the issue of online privacy which involves internet adtracking and packet sniffing. Online advertisement agencies use cookies which are small pieces of data sent by a web server to store on a web browser for ad-tracking ("What are cookies?" n.d.). Cookies themselves are tolerable as they allow websites to store website personalization information, online shopping carts, and login information; however, when they are used for ad-tracking, privacy becomes a huge concern. Advertisement agencies use cookies to track the online advertisements that users view the most and build profiles on users to personalize advertisement data. The most threatening part of ad-tracking is the possibility of advertisement agencies to sell browsing habits to other advertisement agencies, insurance companies, and employers.

The issue of packet sniffing was also explored. Packet sniffing programs collect network data so that the user can monitor its target. Packet sniffing programs are similar to telephone wiretapping devices as they can be used to monitor what an individual is doing on the internet ("Sniffing," n.d.). The use of these programs is not always unjustified; for example, a corporation or school could monitor their networks to make sure people are on task. However, these programs considerably easier to acquire than telephone wiretapping devices since numerous packet sniffing programs can be downloaded online and is possible for any educated internet user to acquire one to spy on an unprotected or public network. Powerful actors in this issue include advertisement agencies who invade privacy for revenue and internet privacy advocates (on the opposing side). These matters are far too important to be left ignored and awareness needs to be raised, such is the purpose of this research informed action project. 


\section{Focus of the Study}

The primary focus of the public opinion poll was to determine the public's interest and concerns regarding internet privacy, coltan mining and the environmental impact of computers.
We distributed 140 surveys to students of Erindale Secondary School in Mississauga with males and females of varying ages. We verified that all of the questions were answered and then the data was recorded manually.

\section{Summary of Results}

The results of the public opinion poll have shown a general lack of understanding on the issues of internet privacy and coltan mining. The majority of students (65\%) reported that they felt safe when browsing the internet (Figure 1) and most reported to be moderately concerned with internet privacy (Figure 3). These results were alarming as the majority of students do not have a decent understanding of what is packet sniffing and adtracking (Figure 2), yet both are key ways through which people's privacy is invaded. Additionally, about $73 \%$ of students reported not knowing how to protect themselves from being vulnerable to ad-tracking and packet sniffing (Figure 4). It is crucial that students become more aware of online privacy as online tracking continues to increase and packet sniffing programs are becoming easier to attain. Although 93 out of 140 students claimed they know some of the environmental impacts of computers (Figure $6)$, only $26 \%$ of students reported knowing about the negative effects of coltan mining (Figure 5). With the significant use of coltan in technological devices and the numerous negative impacts that coltan mining has in the Democratic Republic of Congo and surrounding countries, it is crucial that students become more aware of coltan mining. The lack of public interest regarding online privacy and coltan mining is worrisome. 


\section{Discussion}

Most technological devices ten years ago have been rendered obsolete as a result of advancements in science. Between 1997 and 2007, it has been estimated that 500 million computers became obsolete in the United States and it is projected that 2 billion computers will be in use by 2015 worldwide (Yates, Daley \& Gray, 2007). The researchers and engineers who make modern day technology have to solve several problems that essentially could not have been solved ten years ago. This can be attributed to the incentives to find new solutions; however, the main problems that are being solved are not the problems that need solving. The focus needs to be redirected from cheaper and newer technologies to solutions that are healthier, safer and more fair. It is the modern consumers of developed countries that are purchasing and using these technologies that have the biggest potential impact on corporations. Unfortunately, youth today do not have the incentive to become aware of several environmental and social issues and subsequently take action. With a random sample of 140 teenage students at Erindale Secondary School, the results of the study conducted demonstrate the extent to which current issues are overlooked. The data shows that the majority of teenagers ages 14-18 are relatively unconcerned of internet privacy, with a minority educated in cookies, packet sniffing and adtracking. While the sample size had access to this information it is the lack of concern that is alarming. With an increase in awareness, this project attempts to invoke social activism in others, as there is not only an issue with online privacy but a growing ecological problem.

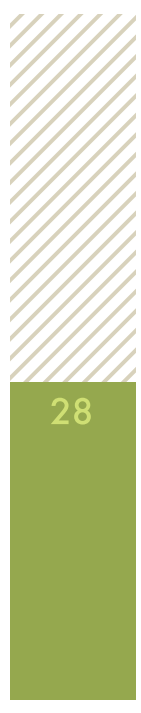

○

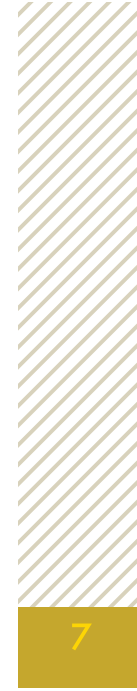

$-$

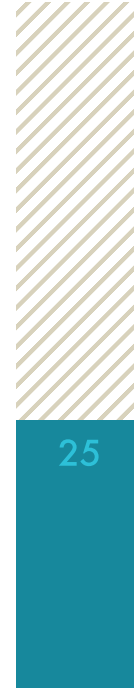

N

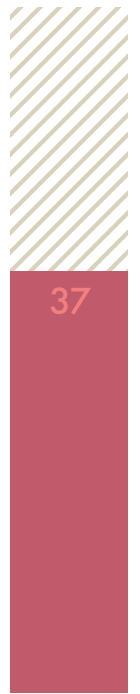

$m$

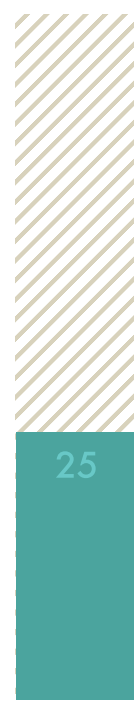

$\nabla$

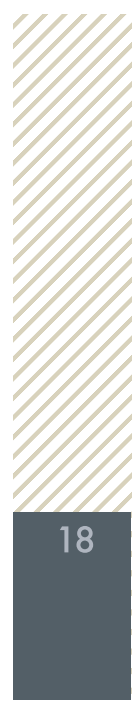

น
Figure 3: How much students are concerned with internet privacy on a scale of 0 to 5

Coltan mining has severe impacts in developing countries, and while youth in developed countries have the ability to make a significant difference with respect to these issues, they remain unaware. Eastern Congo, where a civil war killed 4 million people over the past decade, has $80 \%$ of world's coltan ("Coltan, gorillas and cellphones,"n.d.). The UN has published a report and are making efforts to regulate the mining and sale of coltan through the employment of stringent policies (United Nations, 2001). Coltan is heavily 
relied on by the Rwandan army; it has been reported that they earned over $\$ 250$ million in less than 18 months (United Nations, 2001). In addition, the military forces of Uganda and Burundi are also involved in smuggling coltan out of Congo for resale in Belgium. A report to the United Nations Security Council has called for a pause on purchase and trade in of resources from Republic of Congo, due to the civil war in progress that has dragged in the surrounding countries
(“Coltan, gorillas and cellphones,"n.d.). Unfortunately, consumers in developed countries only see the finished product, and tend to forget that goods require resources; for example, according to a study conducted by the UN, $240 \mathrm{~kg}$ of fossil fuels, $22 \mathrm{~kg}$ of chemicals and 1.5 tonnes of water are required in the manufacturing process of a computer and its screen (United Nations, 2001). This lack of concern and social activist stagnancy can largely be attributed to a diffusion of responsibility. Students do not recognize the impact they can have and believe that others in the macrocosm will solve the issues; as a result, they are less likely to attempt to take direct action themselves. While a short phone battery life may indeed be a problem, the goal needs to be redirected to prolonging current life on this planet. We cannot buy a better life, but we can take measures to ameliorate conditions by educating ourselves and taking action.

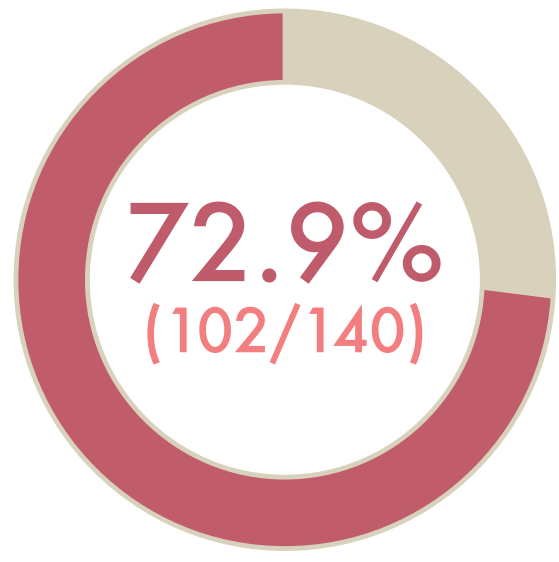

Figure 4: Students who do not know how to prevent packet sniffing or adtracking

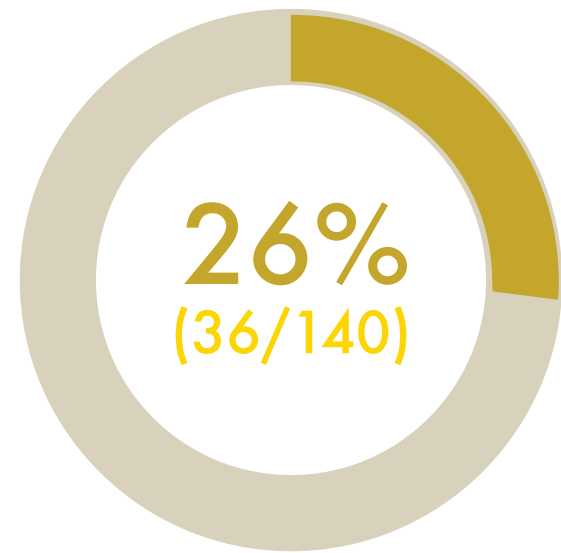

Figure 5: Students who are know about the negative effects of coltan mining

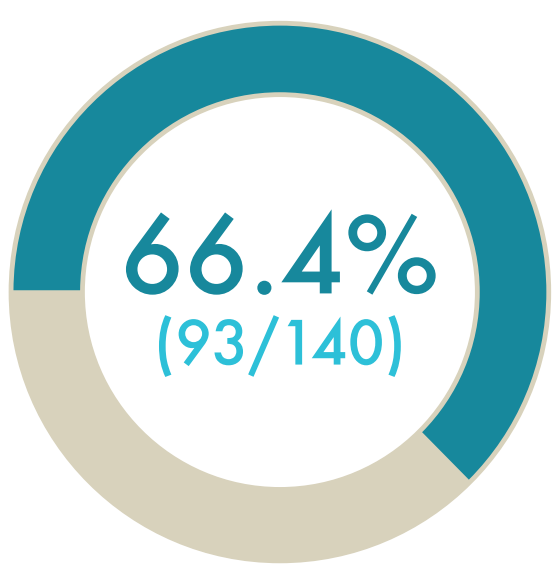

Figure 6: Students who are aware of environmental impacts of computers

\section{References}

Coltan, gorillas and cellphones. (n.d.). Retrieved from http://www.cellular-news.com/coltan/

Hoofnagle, C. J., \& Good, N. (2012, October). Web Privacy Census.

Retrieved from http://www.law.berkeley.edu/privacycensus.htm

United Nations. Report of the Panel of Experts on the Illegal Exploitation of Natural

Resources and Other Forms of Wealth of the Democratic Republic of the Congo. (2001,

April 12). Retrieved from http://www.un.org/News/dh/latest/drcongo.htm

Sniffing. (n.d.). Retrieved from http://cs.baylor.edu/-donahoo/tools/sniffer/sniffingFAQ.htm

What are cookies?. (n.d.). Retrieved from http://www.cookiecentral.com/cm002.htm

Yates, S., Daley, E., \& Gray, B. (2007, June 11). Worldwide PC Adoption Forecast, 2007 To 2015. Retrieved

from http://www.forrester.com/Worldwide+PC+Adoption+Forecast+2007+To+2015/fulltext/-/E-RES42496 